\title{
Nitric Oxide Release Using Natural Rubber Latex as Matrix
}

\author{
Rondinelli Donizetti Herculano ${ }^{\text {a* }}$, Lee Chen Tzu ${ }^{\mathrm{b}}$, Cecilia Pereira Silvac, Carlos Alberto Brunello , \\ Álvaro Antônio Alencar de Queiroz, Angela Kinoshita ${ }^{\mathrm{d}, \mathrm{c}}$, Carlos Frederico de Oliveira Graeff ${ }^{\mathrm{e}}$ \\ ${ }^{a}$ Departamento de Ciências Biológicas, Faculdade de Ciências e Letras de Assis, UNESP, \\ Av. Dom Antonio, 2100, CEP 19806-900, Assis, SP, Brazil \\ ${ }^{b}$ Universidade Sagrado Coração, \\ Rua Irmã Arminda, 10-50, CEP 17011-160, Bauru, SP, Brazil \\ ${ }^{c}$ Departamento de Física e Matemática, Faculdade de Filosofia, Ciências e Letras de Ribeirão Preto, USP \\ Av. Bandeirantes, 3900, CEP 14040-901, Ribeirão Preto, SP, Brazil \\ ${ }^{d}$ Departamento de Física e Química, Universidade Federal de Itajubá - UNIFEI, \\ Av. BPS, 1303, CEP 37500-903, Itajubá, MG, Brazil \\ e Departamento de Física, Faculdade de Ciências, UNESP, \\ Av. Luis Edmundo Carrijo Coube, 14-01, CEP 17033-360, Bauru, SP, Brazil
}

Received: March 16, 2011; Revised: June 16, 2011

\begin{abstract}
Nitric oxide (NO) is a diffusible messenger that has been involved in numerous physiological processes ranging from vasodilatation and antimicrobial properties to wound healing. The beneficial effects can be attributed to the role NO plays in angiogenesis, inflammation and tissue remodeling. In the present work, a polymeric device for the sustained site specific delivery of nitric oxide using a latex rubber matrix from Hevea brasiliensis which encapsulates the spin trap iron(II)- diethyldithiocarbamate complex (FeDETC) was developed. The release profiles of NO from latex rubber matrix were studied and stability studies were carried out. Electron Paramagnetic Resonance (EPR) signal of NO was detected in the membrane exposed to ambient atmosphere at room temperature $\left(25^{\circ} \mathrm{C}\right)$ even after 350 hours. FTIR spectroscopy data indicated that NO-FeDETC retained its structural and spectroscopic properties upon encapsulation in the latex matrix. The NO delivery system developed in this work as a membrane, presented high stability.
\end{abstract}

Keywords: nitric oxide, latex membrane, biomaterials, drug delivery system

\section{Introduction}

Nitric oxide (NO) is an important cell-signaling molecule whose role in a variety of cellular processes, such as vascular relaxation ${ }^{1-4}$, neurotransmission, platelet aggregation and immune regulation ${ }^{5}$. Over recent years it has become apparent that NO has important effects on bone remodeling.

Natural rubber latex (NRL, cis-1,4-polyisoprene) extracted from Hevea brasiliensis has been widely used as raw material in the manufacturing of gloves, condoms, balloons, and other medical and dental devices. Typically for those applications, the processing of NRL was basically the same as those found in the tire's industry. However recently, several new biomedical applications for NRL have been proposed using a different manufacturing process (NRLb) ${ }^{6-11}$. Of special interest, NRL has shown to stimulate angiogenesis, cellular adhesion and the formation of extracellular matrix ${ }^{12-14}$, promoting the replacement and regeneration of tissue ${ }^{15-17}$. In fact, NRLb is now commercialized in Brazil and other 60 countries as a band-aid curative $\left(\right.$ BIOCURE $^{\circledR}$ ) for the treatment of ulcers in diabetic patients among other applications ${ }^{17}$.

Nitric oxide (NO) is an important physiological cellular signaling molecule that functions in a diverse range of cellular processes playing many biological roles as a major defense molecule against intercellular bacteria, tumor cells and aiding in wound repair. NO is produced by intracellular enzyme nitric oxide synthase (NOS), but can permeate cell membranes to reach extracellular spaces and adjacent cells ${ }^{18}$.
Many methods for quantification of NO in biologic media have been reported, including colorimetry, fluorometry, electrochemical methods, and electron paramagnetic resonance (EPR) ${ }^{19}$. Among these techniques the electron paramagnetic resonance (EPR) using diethylthiocarbamates complexes (FeDETC) as spin trap is very promising technique due to their sensitivity, selectivity, and possibility for application in vivo. In FeDETEC the electron-donating group on the dithiocarbamate ligand is favorable for enhancing the sensitivity of NO detection due to the stabilization of the Fe(II) complex form. However, these complexes are unstable for long-term measurements ${ }^{20}$.

To overcome the instability at long-term measurements FeDETCNO complexes, we developed in a previous work a sensor ${ }^{6-7}$ based on the encapsulation of FeDETC in NRL matrix. NRL may be an interesting material for applications as wound healing due to their biocompatible properties and ease of handling due to its good mechanical properties ${ }^{8,21-23}$.

The increasing evidence that NO plays a key role in wound healing suggests that the NRL-FeDETC matrix may be an interesting biomaterial for in situ delivery of NO for wound healing. It is well known that Diabetes Mellitus patients show impaired wound healing, posing a major clinical challenge. It has been shown that the production of multiple growth factors is impaired in patients with diabetes are directly related to the low NO production ${ }^{24-26}$. 
In this work, we propose a NO release system based on the encapsulation of FeDETC in a NRL matrix for the sustained and controlled delivery of NO for future applications in medicine as wound healing. To characterize the release behavior of NO by this system, the NRL-FeDETC system was exposed to ambient atmosphere (humidity $60 \%, 25^{\circ} \mathrm{C}$ ) and the EPR signal of NO in the membrane was monitored as function of time.

\section{Materials and Methods}

Natural rubber latex (NRL) used in the present study was commercial high-ammonia natural rubber latex (ESALQ-USP, Piracicaba, Brazil) of about $60 \%$ dry rubber content (DRC). After extraction, ammonia was used to keep the latex liquid. The deproteinization of natural rubber latex was performed by centrifugation at $8,000 \mathrm{~g}$. The cream fraction after centrifugation was re-dispersed to make $60 \mathrm{wt}$. (\%) of dry rubber content latex and was washed twice by centrifugation to prepare the deproteinized natural rubber latex and then reduce the cytotoxic protein content on NRL.

Ferric chloride hexahydrate $\left(\mathrm{FeCl}_{3} .6 \mathrm{H}_{2} \mathrm{O}, 99.5 \%\right)$, dimethylformamide (DMF, 99.0\%, Acros Organics) and sodium dietyldithiocarbamate (DETC, 99.0\% Acros Organics) were used as received. The FeDETC solution was prepared by using $12 \mathrm{mg}$ of $\mathrm{FeCl}_{3}$ and $20 \mathrm{mg}$ of DETC in $3 \mathrm{~mL}$ of DMF under magnetic stirring for 10 minutes at room temperature $\left(25^{\circ} \mathrm{C}\right)$.

In this work, the encapsulation of FeDETC in NRL membranes was attained after mixing $2 \mathrm{~mL}$ of natural rubber with FeDETC $(2 \mathrm{~mL})$. The NRL-FeDETC solution was cast on a Petri glass dish at room temperature $\left(25^{\circ} \mathrm{C}\right)$ for 48 hours. This methodology provided elastic NRL-FeDETC membranes with thickness of $(0.512 \pm 0.005) \mathrm{mm}$.

$\mathrm{NO}$ was generated in an aqueous solution by mixing $\mathrm{NaNO}_{2}$ $10 \mathrm{mM}(250 \mu \mathrm{L})$, deionized water $(750 \mu \mathrm{L})$ and $\mathrm{Na}_{2} \mathrm{~S}_{2} \mathrm{O}_{4}(145 \mathrm{mg})$ in an eppendorf ${ }^{\circledR}$ tube of $1.5 \mathrm{~mL}$. In the presence of sodium dithionite $\left(\mathrm{Na}_{2} \mathrm{~S}_{2} \mathrm{O}_{4}\right)$ nitrite is reduced to NO. The saturated concentration of $\mathrm{NO}$ in this solution was $2.2 \mathrm{mM}$.

Electron Paramagnetic Resonance (EPR) experiments were done in a computer interfaced Varian E-4 X-band spectrometer at room temperature. For EPR measurements, the membranes were removed from the solution, dried at room temperature $\left(25^{\circ} \mathrm{C}\right)$ for 48 hours and inserted in a quartz tube and the signal of the NO:FeDETC complex was observed. To maximize signal to noise ratio various spectra were summed up, typically at least 10 . To avoid sample repositioning induced errors for the stability measurements, the sample was kept inside the resonant cavity. A reference sample with a known and stable amount of spins was used before each measurement.

The rate of NO diffusion from NRL membranes was measured by Fourier transform infrared (FTIR) spectroscopy over 300 hours. The spectra were performed at room temperature $\left(25^{\circ} \mathrm{C}\right)$ by using a NICOLET 380 (Thermo Electron Co., USA) spectrophotometer in the attenuated total reflectance (ATR) mode $\left(4000-500 \mathrm{~cm}^{-1}\right)$ with resolution of $4 \mathrm{~cm}^{-1}$.

\section{Results and Discussion}

The main component of NRL is cis-1,4-polyisoprene with a high degree of long chain branching generally associated with the presence of non-hydrocarbon groups distributed along the chains. One of the most important of the non-hydrocarbon group's presents in NRL is the aldehyde group, which is thought to be responsible for crosslinking between the chains in $\mathrm{NRL}^{27}$ and their concentration varying from clone to clone ${ }^{28}$. Other compounds, such as lipids, neutral glycolipids and phospholipids, amount to $1.4-3.2 \%$. NRL contains $0.95 \%$ protein that upon centrifugation about $27.2 \%$ of this stays in the rubber fraction ${ }^{29}$. Figure 1 illustrates the chemical structure of isoprene polymer from NRL.

FT-IR spectra of natural rubber before FeDETC encapsulation are presented in Figure 2. Initially, the absorption band observed at $572 \mathrm{~cm}^{-1}$ corresponds to the $\mathrm{C}-\mathrm{C}-\mathrm{C}$ deformation of NRL backbone. The cis1,4-polyisoprene absorption band of strong amplitude corresponding to $=\mathrm{CH}$ out of plane bending is observed at $836 \mathrm{~cm}^{-1}$; the trans isomer has no absorption at this wavelength. A closer inspection of the infrared spectra reveals that it has absorbance bands at $1240 \mathrm{~cm}^{-1}$, corresponding to $\mathrm{O}-\mathrm{P}-\mathrm{O}$ asymmetric stretching of phospholipids indicating the presence of associated phospholipids at the rubber chain, since free fatty acids and free phospholipids were removed by centrifugation ${ }^{28,30}$. The absorptions bands at $1375 \mathrm{~cm}^{-1}\left(\mathrm{CH}_{2}\right.$ deformation), $1394 \mathrm{~cm}^{-1}$ and $1432 \mathrm{~cm}^{-1}$ and $1494 \mathrm{~cm}^{-1}$ are characteristics of $\mathrm{CH}_{2}$ deformation and $\mathrm{CH}_{3}$ asymmetric stretching, respectively. The absorption band at $1647 \mathrm{~cm}^{-1}$ correspond to $\mathrm{C}=\mathrm{C}$ stretching in cis-1,4-polyisoprene. The $\mathrm{CH}_{2}$ symmetric stretching vibrations are observed at the region $2852 \mathrm{~cm}^{-1}-2925 \mathrm{~cm}^{-1}$. The $\mathrm{CH}_{3}$ asymmetric stretching in FT-IR of NRL membranes is observed at $2961 \mathrm{~cm}^{-1}$. These FT-IR correlations for NRL are consistent with the earlier works ${ }^{28-30}$. In addition, Figure 2 also shows a broad peak at approximately $3200-3500 \mathrm{~cm}^{-1}$. This absorption band might be related to the presence of a hydroxyl group, which appears to be generated after the hydrolytic ring opening of epoxy group's formed during the casting of NRL membranes.

Thiol-substituted compounds, as FeDETC, tend to give rise to very weak absorptions in IR spectrum. The higher mass of sulfur, results in the characteristic group frequencies occurring at lower frequencies. The C-S stretching vibrations of FeDETEC tend to give rise to very weak absorptions in IR spectrum. The principal characteristics of FT-IR absorption bands of NRL-FeDETC membranes are shown in Figure 4. In the IR spectra of NRL-FeDETC the $\mathrm{CN}$ stretching frequencies are observed at $1494 \mathrm{~cm}^{-1}, 1358 \mathrm{~cm}^{-1}$ and $1270 \mathrm{~cm}^{-1}$ The absorption band at $1210 \mathrm{~cm}^{-1}$ corresponds to $\mathrm{CN}$ stretch of tertiary amine from FeDETC (Figure 3). The C-S stretching frequency appears close to $990 \mathrm{~cm}^{-1}$ and is characteristic for FeDETC (Figure 3$)^{31}$. The absorption band for the Fe-S was not observed in NRL-FeDETC. However, our density functional (DFT) calculations of Fe-S vibrations in FeDETEC (not shown) indicate that this absorption band appears to be active in the IR region between $350-240 \mathrm{~cm}^{-1}$. These calculated results are found to be in excellent agreement with

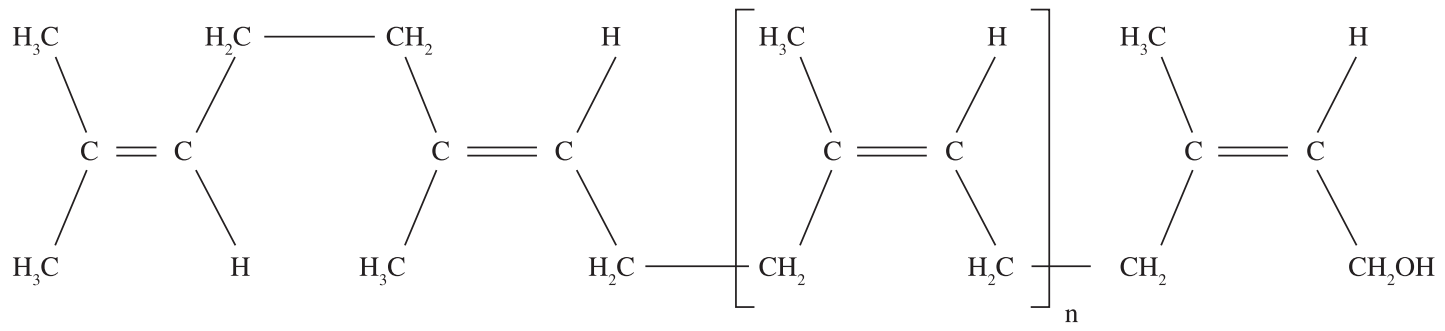

Figure 1. Chemical structure of cis-1,4-polyisoprene from natural rubber. 


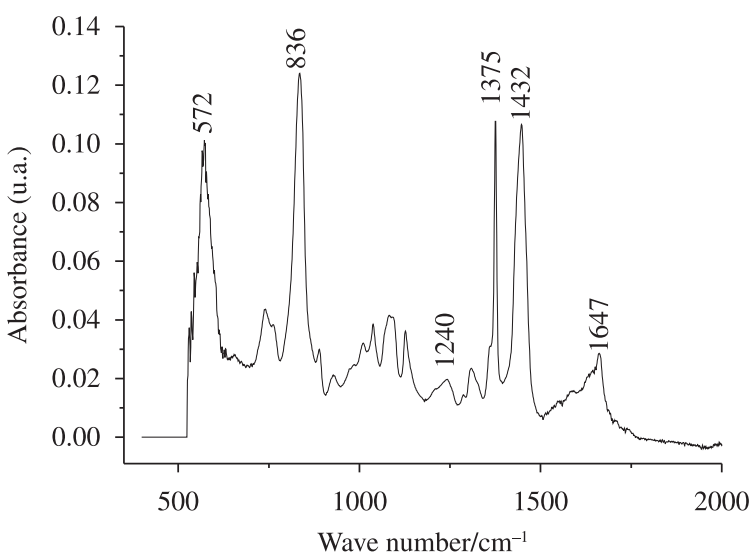

(a)

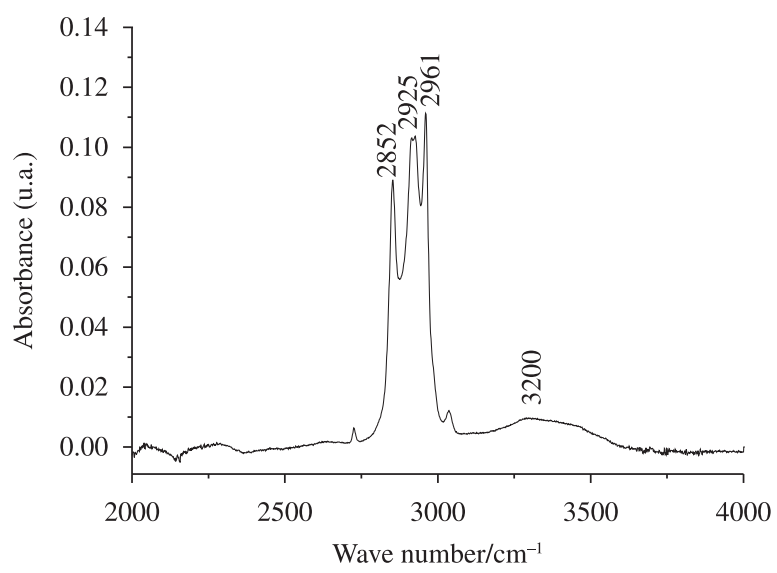

(b)

— Natural rubber latex

Figure 2. FT-IR spectra of the natural rubber membranes in potassium bromide disc. The characteristic bands for cis-1,4-polyisoprene are indicated with their wave numbers.

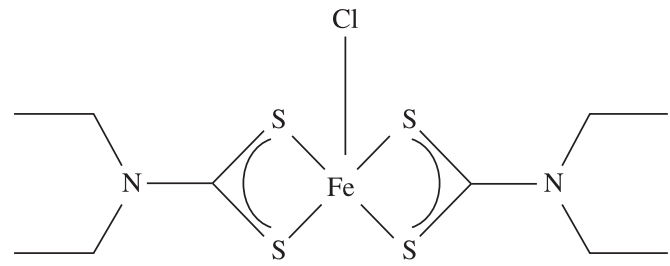

Figure 3. Illustration of the molecular structure of FeDETEC.

the $\mathrm{Fe}(\mathrm{III})$ spin crossover behavior studied by infrared spectroscopy and might be assigned with $v(\mathrm{Fe}-\mathrm{S})$ vibrations ${ }^{32}$.

Works have demonstrated that natural rubber lattices may be vulcanized by using diethyldithiocarbamates ${ }^{33}$. However, their amplitudes are essentially dependent of their concentration on latex membranes and a quantitative study about the FeDETC influence on latex vulcanization was not possible in this work. No significant differences have been found in other IR spectral region of NRL-FeDETC relatively to NRL suggesting no chemical interaction between FeDETC and NRL.

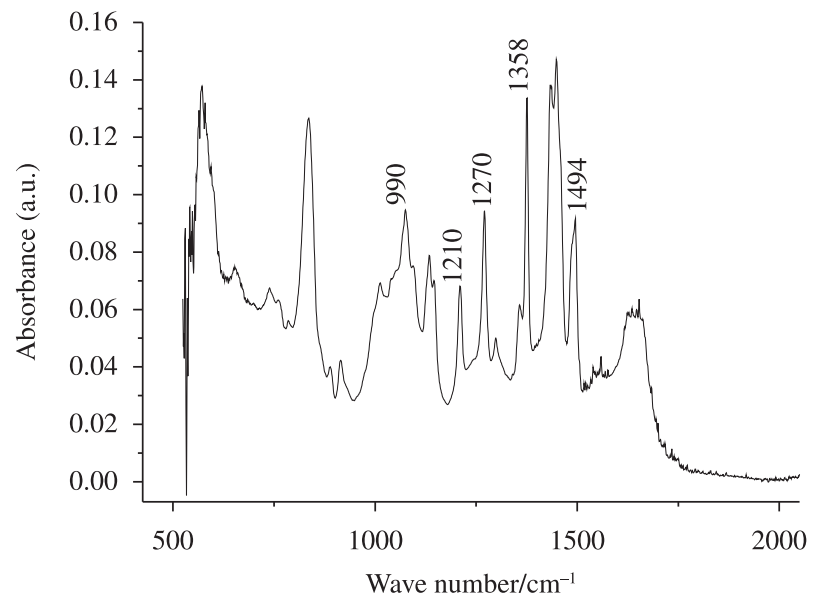

(a)

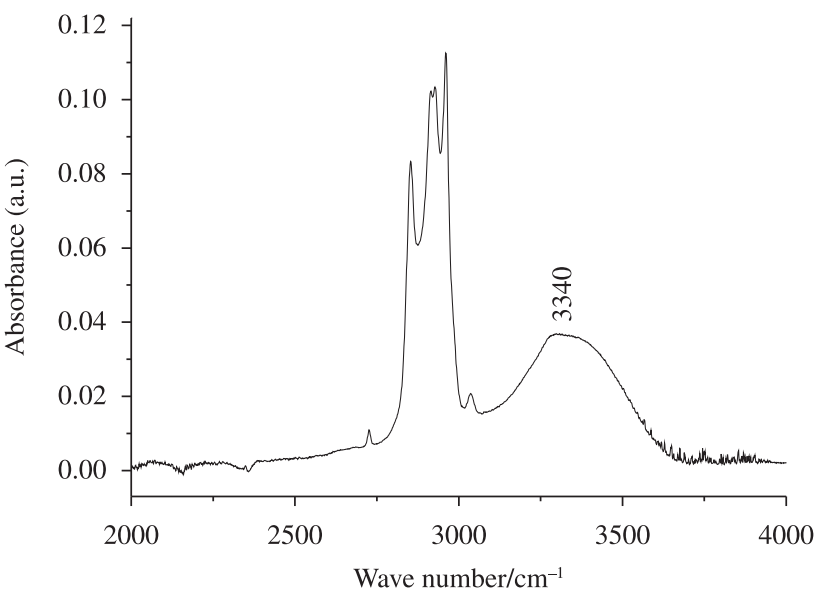

(b)

\section{Natural rubber latex + FeDETC}

Figure 4. FT-IR spectra of the natural rubber membranes after complexation of Fe-DETC. FeDETC concentration: $14.8 \mathrm{mM}^{7}$.

Another important parameter, which concerns the sensitivity of the NO drug delivery system, is the density of spin traps ${ }^{34}$ incorporated into the polymer matrix. In this case where the polymer matrix is NRL, FeDETC could have two functions. Since DETC contains sulphur, it acts as a crosslinking agent, which accelerates the polymerization, or in other words the rubber formation. In fact, as soon as DETC is dropped into the latex solution, rubber is formed in an uncontrolled way at room temperature $\left(25^{\circ} \mathrm{C}\right)$. The other function of FeDETC is to trap NO. As already mentioned, to maximize signal to noise ratio various spectra were summed up, typically at least 10. As shown in Figure 5, the EPR signal amplitude decreases with time.

In Figure 6 the normalized EPR signal amplitude (per membrane mass unit) just after the membrane was taken from the NO solution is plotted as a function of time. As can be seen, the signal decreases with time until it vanishes. For these measurements the membrane was immersed in a $2.5 \mathrm{mM}$ NO solution for 2 hours, and then left in ambient atmosphere. Notice the small decrease in signal amplitude even after 350 hours for samples left in ambient atmosphere.

According to the literature ${ }^{6,7}$, NRL associated to FeDETC-NO are easy to manipulate, allow species detection and concentrations 


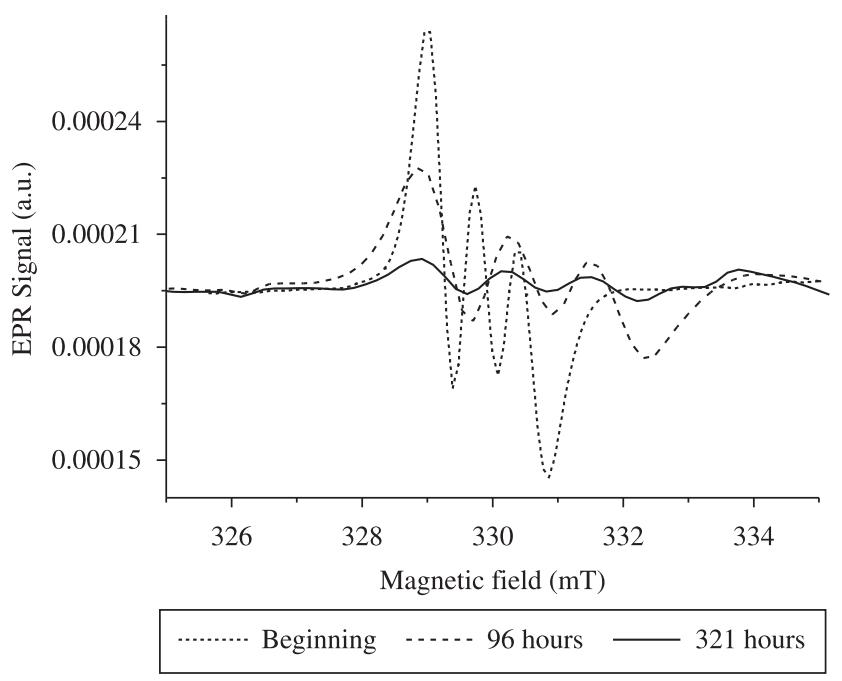

Figure 5. Typical EPR spectra from FeDETC:NO in Latex matrix at room temperature. These spectra were taken several hours after immersion in the NO solution. Notice that signal amplitude decrease with the time.

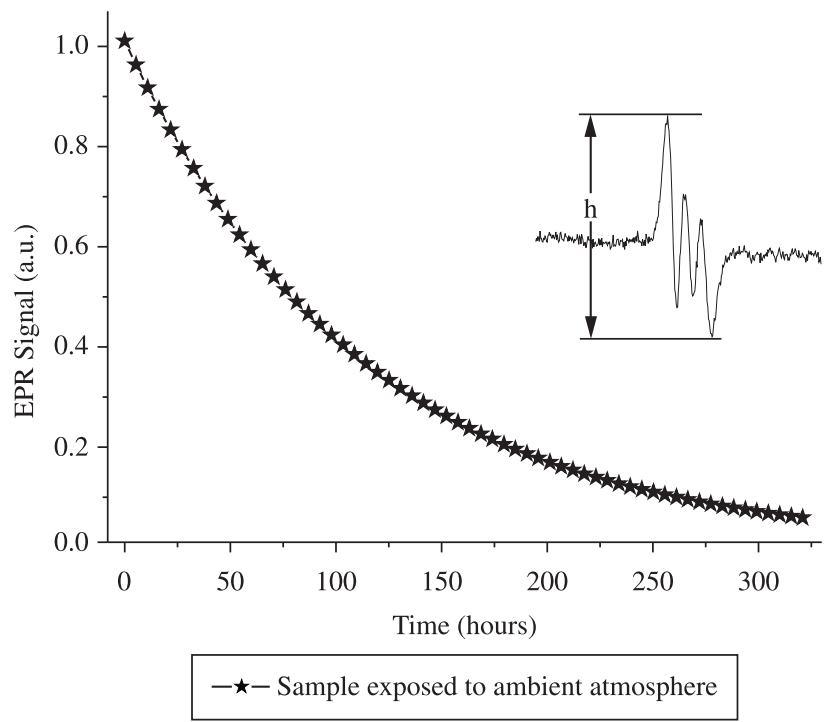

Figure 6. EPR signal amplitude as a function of time. The insert graph shows a typical EPR spectrum for our NO delivery system.

measurements with few sample contamination. These characteristics indicate that latex rubber may be a good choice for a NO delivery system, with superior mechanical properties. The samples are very stable: the signal amplitude of NO could be detected even after 350 hours exposed to ambient atmosphere. As NO is an early mediator of the inflammatory process associated to tissue regeneration and the NRL presented interesting biological properties associated to healing, this new drug delivery system is a promising biomaterial.

\section{Conclusion}

We propose a novel NO delivery system made of a spin trap (iron(II)-diethyldithiocarbamate complex, FeDETC) encapsulated in a NRL matrix. The rate release of NO in this system was observed by EPR, exposing the sample to ambient atmosphere. The results indicate the sustained delivery of NO from NRL matrix for up to 350 hours. FTIR spectroscopy showed that NO/FeDETC when encapsulated in NRL has its properties and structure preserved which is relevant for its possible application as a biomaterial.

\section{Acknowledgements}

We are grateful to J. L. Aziani for technical support. This work received financial support from FAPESP, CNPq/IMMP and CAPES.

\section{References}

1. Moncada S, Palmer RMJ and Higgs EA. Nitric oxide: Physiology, pathophysiology and pharmacology. Pharmacological Reviews. 1991; 43:109-142.

2. Archer S. Measurement of nitric oxide in biological models. FASEB Journal. 1993; 7:349-360.

3. Rees DD, Palmer RM and Moncada S. Role of endothelium-derived nitric oxide in the regulation of blood pressure. Proceedings of the National Academy of Sciences USA. 1989; 86:3375-3378. http://dx.doi. org/10.1073/pnas.86.9.3375

4. Nagassaki S, Herculano RD, Graeff CFO and Tanus-Santos JE. eNOS T-786C polymorphism affects atorvastatin-induced changes in erythrocyte membrane fluidity. European Journal of Clinical Pharmacology. 2009; 65(4):385-392. http://dx.doi.org/10.1007/s00228-008-0602-7

5. Muriel $P$ and Sandoval G. Nitric oxide and peroxynitrite anion modulate liver plasma membrane fluidity and $\mathrm{Na}(+) / \mathrm{K}(+)$-ATPase activity. Nitric Oxide. 2000; 4:333-342. http://dx.doi.org/10.1006/niox.2000.0285

6. Herculano RD, Brunello CA and Graeff CFO. Solid state Nitric Oxide sensor using a latex rubber matrix. Macromolecular Symposia. 2006; 245-246:529-532. http://dx.doi.org/10.1002/masy.200651376

7. Herculano RD, Brunello CA and Graeff CFO. Optimization of a novel Nitric Oxide Sensor using a latex rubber matrix. Journal of Applied Sciences. 2007; 7(23):3801-3805. http://dx.doi.org/10.3923/ jas.2007.3801.3805

8. Balabanian CACA, Coutinho Netto J, Lamano-Carvalho TL, Lacerda SA and Brentegani LG. Biocompatibility of natural latex implanted into dental alveolus of rats. Journal of Oral Science. 2006; 48(4):201-205. http://dx.doi.org/10.2334/josnusd.48.201

9. Frade MAC, Valverde RV, Assis RVC, Coutinho-Netto J and Foss NT. Chronic phlebopathic cutaneous ulcer: a therapeutic proposal. International Journal of Dermatology. 2001; 40(3):237-240. http://dx.doi. org/10.1046/j.1365-4362.2001.00977-2.x

10. Neves-Junior WFP, Ferreira M, Alves MCO, Graeff CFO, Bernardes MS, Coutinho-Netto J et al. Influence of fabrication process on the final properties of natural-rubber latex tubes for vascular prosthesis. Brazilian Journal of Physics. 2006; 36(2B):586-591. http://dx.doi.org/10.1590/ S0103-97332006000400021

11. Ciapetti G, Stea S, Pizzoferrato A, Checchi L and Pelliccioni GA. A latex membrane, as an alternative device in the GTR technique: preliminary report on its biocompatibility. Journal of Materials Science: Materials in Medicine. 1994; 5(9-10):647-650. http://dx.doi.org/10.1007/BF00120348

12. Mrué F, Coutinho-Netto J, Ceneviva R, Lachat JJ, Thomazini JA and Tambelini H. Evaluation of the biocompatibility of a new biomembrane. Materials Research. 2004; 7(2):277-283.

13. Ereno C, Catanzaro-Guimarães SA, Pasetto S, Holgado L, Herculano $\mathrm{RD}$, Silva $\mathrm{CP}$ et al. Latex use as an occlusive membrane for guided bone regeneration. Journal of Biomedical Materials Research. 2010; 95A (3):932-939. http://dx.doi.org/10.1002/jbm.a.32919

14. Herculano RD, De Queiroz, AAA, Kinoshita A, Oliveira Junior ON and Graeff CFO. On the release of metronidazole from natural rubber latex membranes. Materials Science \& Engineering C: Biomimetic Materials, Sensors and Systems. 2011, 31:272-275.

15. Mendonça RJ and Coutinho-Netto J. Aspectos celulares da cicatrização. Anais Brasileiros de Dermatologia. 2009; 84(3):257-262. 
16. Herculano RD, Pereira CP, Ereno C, Catanzaro-Guimarães SAC, Kinoshita A and Graeff CFO. Natural rubber latex used as drug delivery system in guided bone regeneration (GBR). Materials Research. 2009; 12(2):253-256. http://dx.doi.org/10.1590/S1516-14392009000200023

17. Pele Nova-Biocure. Available from: $\langle$ http://www.pelenova.com.br/site/>. Access in: 07/2009.

18. Miles PR, Bowman L and Huffman L. Nitric oxide alters metabolism in isolated alveolar type II cells. AJP - Lung Physio. 1996, 27(1):L23-L30.

19. Tarpey MM, Wink DA and Grisham MB. Methods for detection of reactive metabolites of oxygen and nitrogen: in vitro and in vivo considerations. American Journal of Physiology - Regulatory, Integrative and Comparative Physiology. 2004, 286:431-444. http://dx.doi.org/10.1152/ajpregu.00361.2003

20. Charlier N, Preat V and Gallez B. Evaluation of Lipid-Based Carrier Systems and Inclusion Complexes of Diethyldithiocarbamate-Iron to Trap Nitric Oxide in Biological Systems. Magnetic Resonance in Medicine. 2006, 55:215-218. http://dx.doi.org/10.1002/mrm.20746

21. Mendonça R J, Maurício VB, De Bortolli Teixeira L, Lachat JJ and Coutinho-Netto J. Increased vascular permeability, angiogenesis and wound healing induced by the serum of natural latex of the rubber tree Hevea brasiliensis. Phytotherapy Research. 2009; 24(5):764-768.

22. Ferreira M, Mendonça RJ, Coutinho-Netto J and Mulato M. Angiogenic properties of natural rubber latex biomembranes and the serum fraction of Hevea brasiliensis. Brazilian Journal of Physics. 2009; 39:564-569. http://dx.doi.org/10.1590/S0103-97332009000500010

23. Sampaio RB, Mendonca RJ, Simioni AR, Costa RA, Siqueira RC, Correa VM et al. Rabbit Retinal Neovascularization Induced by Latex AngiogenicDerived Fraction: An Experimental Model. Current Eye Research. 2010; 35(1):56-62. http://dx.doi.org/10.3109/02713680903374216

24. Stallmayer B, Kempfer H, Kolb N, Pfeil J and Frank S. Function of Nitric oxide in wound repair; inhibition of nitric oxide synthase in severely impairs wound reepithelization. Journal of Investigative Dermatology. 1999; 113:1090- 1098. http://dx.doi.org/10.1046/j.1523-1747.1999.00784.x

25. Frank S, Kempfer H, Wetzler C and Pfeil J. Nitric oxide drives skin repair: Novel function of an established mediator. Kidney International. 2005; 61:882-888. http://dx.doi.org/10.1046/j.1523-1755.2002.00237.x
26. Hehenberger K, Helborn JD, Brismar K and Hansson A. Inhibited proliferation of fibroblast derived from chronic diabetic wounds and normal dermal fibroblast treated with high glucose is associated with high formation of L-lactate. Wound Repair and Regeneration. 1998; 6 (2):135-141. http://dx.doi.org/10.1046/j.1524-475X.1998.60207.x

27. Angulo-Sanchez JL and Cabollero-Mato P. Long chain branching in natural Hevea rubber - determination by gel permeation chromatography. Rubber Chemistry and Technology. 1981; 54:34-43. http://dx.doi. org/10.5254/1.3535795

28. Tarachiwin L, Sakdapipanich J, Ute K, Kitayama T and Tanaka Y. Structural characterization of $\alpha$-terminal group of natural rubber: 2. decomposition of branch-points by phospholipase and chemical treatments. Biomacromolecules. 2005; 6:1858-1863. http://dx.doi. org/10.1021/bm058004p

29. Tata SJ. Distribution of proteins between the fractions of Hevea latex separated by ultracentrifugation. Journal of the Rubber Research Institute of Malaysia. 1980; 28:77-83.

30. Wong PTT and Mantsch HH. High-pressure infrared spectroscopic evidence of water binding sites in 1, 2-diacylphospholipids. Chemistry and Physics of Lipids. 1988; 46:213-224. http://dx.doi.org/10.1016/00093084(88)90024-2

31. Jensen KA and Krishnan V. IX. Infrared spectra of diselenocarbamate complexes. Acta Chemica Scandinavica. 1970; 24(3):1088-1090. http://dx.doi.org/10.3891/acta.chem.scand.24-1088

32. Van Koningsbruggen PJ, Maeda Y and Oshio H. Iron(III) Spin Crossover Compounds. Topics in Current Chemistry. 2004; 233:259-324.

33. Saendee $\mathrm{P}$ and Tangboriboonrat P. Latex interpenetrating polymer networks of epoxidised natural rubber/poly(methyl methacrylate): An insight into the echanism of epoxidation. Colloid \& Polymer Science. 2006; 284:634-643. http://dx.doi.org/10.1007/s00396-005-1437-8

34. Melo Junior JP, Biazotto JC, Brunello, CA and Graeff CFO. Solid state nitric oxide sensor prepared by sol-gel entrapment of iron(III) diethyldithiocarbamate in a silica matrix. Journal of Non-Crystalline Solids. 2004; 348:235-239. 